\title{
BRPKM
}

Buletin Riset Psikologi dan Kesehatan Mental

http://e-journal.unair.ac.id/index.php/BRPKM

e-ISSN: 2776-1851

ARTIKEL PENELITIAN

\section{Hubungan antara Anonimitas dengan Self-Disclosure pada Pengguna Twitter}

\author{
ANGGITA DEWI NUGRAHANI* \\ Fakultas Psikologi Universitas Airlangga
}

\begin{abstract}
ABSTRAK
Penelitian ini bertujuan mengetahui hubungan antara anonimitas dengan self-disclosure pada pengguna Twitter. Penelitian terdahulu mengungkapkan bahwa anonimitas memungkinkan individu lebih berani untuk berkomunikasi secara online dan melakukan aktivitas self-disclosure. Fenomena tersebut dikenal sebagai online disinhibition effect. Namun, hasil penelitian kuantitatif ini menunjukkan bahwa terdapat korelasi negatif antara anonimitas dengan self-disclosure pada pengguna Twitter. Partisipan pada penelitian ini kurang mengungkapkan dirinya ketika semakin tidak teridentifikasi secara visual.
\end{abstract}

Kata kunci: anonimitas, self-disclosure, pengguna twitter

\section{ABSTRACT}

This study aims to determine the relationship between anonymity and self-disclosure on Twitter users. Previous research revealed that anonymity allows individuals to communicate more boldly and disclose themselves more when they are online. This phenomenon is known as the online disinhibition effect. However, the result of this quantitative study indicates that there is a negative correlation between anonymity and self-disclosure on Twitter users. Participants in this study are less selfdisclosing when they are less visually identified.

Keywords: anonymity, self-disclosure, twitter users

Buletin Penelitian Psikologi dan Kesehatan Mental (BRPKM), 2021, Vol. 1(2), 1427-1434

*Alamat korespondensi: Fakultas Psikologi Universitas Airlangga, Kampus B Universitas Airlangga Jalan Airlangga 4-6 Surabaya 60286. Surel: anggita.dewi.nugrahani-2017@psikologi.unair.ac.id

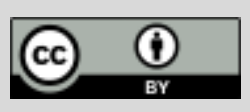

Naskah ini merupakan naskah dengan akses terbuka dibawah ketentuan the Creative Common Attribution License (CC-BY-4.0) (http://creativecommons.org/licenses/by/4.0), sehingga penggunaan, distribusi, reproduksi dalam media apapun atas artikel ini tidak dibatasi, selama sumber aslinya disitir dengan baik. 


\section{PENDAHULUAN}

Media sosial sebagai sarana bagi individu untuk berpendapat, membagikan cerita, dapat terhubung dengan orang lain semakin banyak digunakan dalam beberapa tahun terakhir (Deodhar dkk., 2017). Twitter menjadi salah satu media sosial dengan sistem microblogging yang paling banyak digunakan tercatat memiliki jumlah pengguna aktif bulanan sebanyak 353 juta dan pengguna aktif harian sebanyak 192 juta sepanjang tahun 2021 (Dean, 2021). Diketahui pada tahun 2020, rata-rata jumlah tweet yang dikirim oleh pengguna Twitter yaitu sebanyak 6.000 tweet/detik, 360.000 tweet/menit, 500 juta tweet/hari, dan 2 miliar tweet/tahun (Sayce, 2021).

Tominaga dkk (2018) menyatakan bahwa ada tantangan besar pagi pengguna Twitter dimana pengguna Twitter diharapkan mampu menyeimbangkan antara keinginan berkomunikasi serta menjaga privasi bagi mereka sendiri. Ini disebabkan karena individu melakukan pengungkapan diri atau self-disclosure secara online dengan membagikan informasi, rahasia, emosi, maupun rasa takut yang dialaminya kepada orang-orang terdekatnya atau bahkan orang asing (Bak dkk., 2012; Suler, 2004). Adanya fitur tweet dimanfaatkan oleh pengguna Twitter untuk menuliskan aktivitasnya, membagikan foto, video, atau gambar, bahkan mampu membagikan lokasi terkini. Konten yang dibagikan oleh pengguna Twitter ini terkadang mengandung informasi pribadi, apabila jika informasi ini bocor maka dapat disalahgunakan orang lain atau pihak yang tidak diinginkan (Deodhar dkk., 2017). Oleh sebab itu, Twitter menjadi salah satu media sosial yang memiliki risiko dalam terjadinya kebocoran privasi (Deodhar dkk., 2017; Mao dkk., 2011).

Selain fitur tweet yang memungkinkan suatu informasi yang diposting penggunanya dapat dilihat serta dibaca oleh followers maupun pengguna lain, fitur lainnya seperti retweet dapat menyebarkan informasi yang diposting penggunanya dalam sebuah tweet secara cepat (Komori dkk., 2021). Aktivitas membagikan ulang tweet orang lain tersebut justru dapat menyebabkan kebocoran privasi, ini disebabkan karena adanya penyebaran informasi dan komentar secara real-time ketika seseorang melakukan retweet pada tweet pengguna lainnya (Meeder dkk., 2010).

Adanya dorongan individu dalam mengungkapkan diri atau self-disclosure dapat disalurkan melalui media sosial (Krämer \& Schäwel, 2020) dengan memberikan informasi mengenai dirinya (Taddicken, 2014). Tujuan individu dalam mengungkapkan diri adalah untuk memperdalam hubungan dengan orang lain (Krämer \& Schäwel, 2020), maupun membuat koneksi baru (Komori dkk., 2021). Namun, pengungkapan diri yang dilakukan secara berlebihan memiliki risiko terhadap privasi penggunanya, dimana informasi pribadi ini berpotensi untuk dapat diidentifikasi serta dijangkau oleh pihak ketiga (Komori dkk., 2021).

Self-disclosure bersifat multidimensi dan salah satu dimensi yang paling sering dihubungkan dengan privacy, yaitu intimacy atau depth (Gruzd \& Hernández-García, 2018). Ma dkk. (2016) menemukan bahwa intimacy dapat meregulasi self-disclosure. Menurut Wheeless \& Grotz (1976) dimensi depth merupakan suatu keintiman dari informasi yang diungkapkan oleh seseorang. Keintiman menurut $\mathrm{Ng}$ (2020) juga menyangkut perasaan hangat yang ditimbulkan dari kedekatan dengan seseorang, adanya hubungan emosional, serta sebuah ikatan hubungan. Keintiman tersebut dapat dikelola individu dengan mengendalikan pengungkapan dirinya (Joinson dkk., 2011). Dienlin (2017) mengatakan bahwa semakin banyak seseorang dalam melakukan pengungkapan informasi yang intim dengan orang lain, maka konteks privasi psikologis juga akan semakin tinggi.

Walther (1996) dalam teori hyperpersonal model menjelaskan bahwa computer-mediated communication (CMC) melibatkan lebih banyak self- disclosure, hal ini terjadi karena adanya interaksi

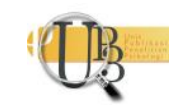


yang lebih intim antar individu melalui CMC dibandingkan secara tatap muka (Kim \& Dindia, 2016). Hyperpersonal model menjelaskan bahwa individu akan merasa mampu berkomunikasi dengan baik tanpa menahan diri di hadapan pasangannya dan menentukan hal-hal yang ingin diungkapkan olehnya (Nguyen dkk., 2012).

Salah satu karakteristik dalam CMC adalah adanya anonimitas. Anonimitas dalam internet dapat menghasilkan self-disclosure (Clark-Gordon dkk., 2019). Anonimitas di internet memengaruhi individu dalam berperilaku ketika online, individu akan cenderung bebas serta lebih berani untuk berkomunikasi secara online dalam keadaan anonim daripada tatap muka secara langsung (ClarkGordon dkk., 2019). Fenomena tersebut disebut sebagai online disinhibition effect (Suler, 2004).

Berdasarkan hasil survei yang dilakukan oleh Kaspersky (2021), diketahui sebanyak 49\% responden menggunakan akun anonim untuk bebas berbicara tanpa memengaruhi reputasi mereka. Kemudian, sebanyak 48\% responden lainnya menjawab akun anonim digunakan untuk menuruti minat rahasia mereka agar tidak diketahui oleh teman-temannya. Lalu, sebanyak 30\% responden menjawab menggunakan akun anonim untuk aktivitas berbagi informasi yang tidak terlalu berbahaya seperti informasi tentang artis favorit, serta mencari minat mereka. Sebanyak 22\% responden lainnya menjawab akun anonim digunakan untuk melakukan penguntitan secara online (Kaspersky, 2021). Hasil survei ini sejalan dengan pernyataan Suler (2004) bahwa anonimitas dapat memberikan dampak yang positif (benign disinhibition) dan dampak yang negatif (toxic disinhibition).

Salah satu tipe anonimitas yaitu anonimitas visual yang merupakan ketidakmampuan individu dalam melihat atau dilihat oleh orang lain serta melibatkan kurangnya representasi visual seperti potret atau terpisah secara fisik (Scott \& Rains, 2020). Joinson dkk (2011) dalam penelitiannya menemukan bahwa informasi mengenai diri sendiri lebih banyak diungkapkan oleh partisipan yang anonim secara visual dibandingkan partisipan yang tidak anonim secara visual. Reduced cues theory (RCT) menjelaskan bahwa kedalaman serta frekuensi self-disclosure akan menjadi lebih besar dengan tidak adanya isyarat visual dan isyarat non-verbal situasional pada interaksi online, seperti ekspresi wajah, intonasi nada, dan perilaku individu pengguna lain (Nguyen dkk., 2012). Oleh sebab itu, anonimitas visual memiliki peran yang cukup besar dalam memengaruhi individu dalam berinteraksi dengan orang lain serta dalam mengungkapkan diri (Nguyen dkk., 2012).

Dari uraian di atas, dapat disimpulkan bahwa Twitter menjadi salah satu media sosial yang dapat di manfaatkan oleh para penggunanya untuk mengungkapkan diri. Namun, terdapat berbagai risiko yang harus dihadapi oleh pengguna Twitter ketika mengungkapkan dirinya melalui Twitter, salah satunya adalah kebocoran privasi yang jika disalahgunakan dapat merugikan para pengguna. Terlepas dari risiko yang ada, individu merasa lebih berani untuk mengungkapkan dirinya jika dilakukan secara online dibandingkan tatap muka karena di internet seseorang akan cenderung menjadi lebih anonim. Hal ini menjadi tujuan peneliti untuk menguji apakah terdapat hubungan antara anonimitas dengan self-disclosure pada pengguna Twitter.

\section{METODE}

\section{Desain Penelitian}

Penelitian ini merupakan penelitian kuantitatif dengan menggunakan survei sebagai metode pengumpulan data. Uji korelasi parsial digunakan untuk mengetahui hubungan antara anonimitas dengan self-disclosure pada pengguna Twitter sambil melakukan kontrol terhadap variabel lainnya 
seperti jenis kelamin, usia, durasi, dan jumlah tweet untuk mendapatkan gambaran yang lebih jelas mengenai hubungan antara kedua variabel tersebut.

\section{Partisipan}

Partisipan pada penelitian ini merupakan pengguna media sosial Twitter dengan jumlah partisipan sebanyak 367 orang. Partisipan penelitian mengisi kuesioner yang disebarkan secara online. Jumlah partisipan dengan jenis kelamin perempuan lebih banyak dibandingkan laki-laki. Partisipan pada penelitian ini paling banyak tergolong pada rentang usia 18-25 tahun dengan jumlah 295 responden dari total 367 responden $(80,4 \%)$. Mayoritas responden merupakan mahasiswa, berpendidikan terakhir Sekolah Menengah Atas (SMA), dan tidak memiliki penghasilan. Selain itu, mayoritas responden menggunakan Twitter kurang dari 3 jam dalam sehari dan memposting kurang dari 5 tweet dalam sehari.

\section{Uji Validitas}

Content Validity Index digunakan untuk mengukur validitas konten dengan memberikan skor 1 sampai dengan 4 pada masing-masing butir dengan tiga aspek, yaitu relevancy, importance, dan clarity. Skor CVI skala anonimitas adalah 1 dan skor CVI skala anonimitas adalah 1. Skor CVI berkisar antara 0-1 sehingga dapat disimpulkan bahwa skala self-disclosure dan skala anonimitas dianggap valid.

\section{Skala Anonimitas}

Anonimitas diukur dengan menggunakan Skala Anonimitas Visual yang dibuat oleh peneliti dengan didasarkan pada Reduced Cues Theory (RCT) oleh Sproull \& Kiesler (1986). Skala ini berjumlah 20 butir pernyataan berdasarkan dua dimensi, yaitu isyarat statis dan isyarat dinamis. Skala ini menggunakan skala Likert dengan 7 pilihan jawaban, yaitu sangat setuju, setuju, agak setuju, netral, agak tidak setuju, tidak setuju, dan sangat tidak setuju. Reliabilitas pada alat ukur anonimitas yaitu sebesar $\alpha=0,913$.

\section{Skala Self-Disclosure}

Self-disclosure diukur dengan menggunakan Revised Self-Disclosure Scale (RSDS) dimensi control of depth dari Leung (2002) yang merupakan adaptasi dari Wheeless \& Grotz (1976) dan telah ditranslasi oleh (Ardi \& Maison, 2014). Skala ini berjumlah 5 butir pernyataan dengan lima pilihan jawaban yaitu sangat setuju, setuju, netral, tidak setuju, dan sangat tidak setuju. Reliabilitas pada alat ukur selfdisclosure yaitu sebesar $\alpha=0,826$.

\section{HASIL PENELITIAN}

\section{Analisis Statistik Deskriptif}

Pada hasil uji ditemukan bahwa pada anonimitas $(M=119,1 ; S D=18,9 ;$ Min=56; Max=140), artinya partisipan memiliki tingkat anonimitas yang sedang. Pada self-disclosure diketahui bahwa $(M=13,53$; $S D=4,69 ; M i n=5 ; M a x=25)$, artinya partisipan memiliki tingkat self-disclosure yang sedang.

\section{Hasil Analisis Data}

Hasil uji korelasi parsial dengan mengontrol jenis kelamin menunjukkan bahwa terdapat korelasi yang kecil dan negatif antara anonimitas dengan self-disclosure $(\mathrm{r}=-0,144, N=367, \mathrm{p}<0,05)$. Dimana sebelum dilakukan kontrol terhadap jenis kelamin, terdapat nilai $(\mathrm{r}=-0,145)$ yang menunjukkan bahwa

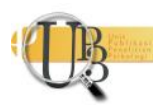


pengendalian jenis kelamin memiliki pengaruh yang sangat kecil terhadap kekuatan korelasi antara anonimitas dengan self-disclosure.

Hasil uji korelasi parsial dengan mengontrol usia menunjukkan bahwa terdapat korelasi yang kecil dan negatif antara anonimitas dengan self-disclosure $(\mathrm{r}=-0,190, N=367, \mathrm{p}<0,05)$. Dimana sebelum dilakukan kontrol terhadap usia, terdapat nilai $r=-0,145$ yang menunjukkan bahwa pengendalian usia memiliki pengaruh yang sangat kecil terhadap kekuatan korelasi antara anonimitas dengan selfdisclosure.

Hasil uji korelasi parsial dengan mengontrol durasi penggunaan Twitter menunjukkan bahwa terdapat korelasi yang kecil dan negatif antara anonimitas dengan self-disclosure $(\mathrm{r}=-0,170, N=367, \mathrm{p}<0,05)$. Dimana sebelum dilakukan kontrol terhadap durasi penggunaan Twitter, terdapat nilai $r=-0,145$ yang menunjukkan bahwa pengendalian durasi penggunaan Twitter memiliki pengaruh yang sangat kecil terhadap kekuatan korelasi antara anonimitas dengan self-disclosure.

Hasil uji korelasi parsial dengan mengontrol jumlah tweet menunjukkan bahwa terdapat korelasi yang kecil dan negatif antara anonimitas dengan self- disclosure $(\mathrm{r}=-0,181, N=367, \mathrm{p}<0,05)$. Dimana sebelum dilakukan kontrol terhadap jumlah tweet, terdapat nilai $(\mathrm{r}=-0,145)$ yang menunjukkan bahwa pengendalian jumlah tweet memiliki pengaruh yang sangat kecil terhadap kekuatan korelasi antara anonimitas dengan self-disclosure.

Dari hasil uji korelasi parsial yang telah dilakukan terhadap jenis kelamin, usia, durasi penggunaan Twitter, dan jumlah tweet, diketahui bahwa terdapat hubungan yang signifikan antara anonimitas dengan self-disclosure pada pengguna Twitter yang ditunjukkan dengan nilai $\mathrm{p}<0,05$ sehingga $\mathrm{H}_{\mathrm{a}}$ diterima dan $\mathrm{H}_{0}$ ditolak. Kemudian, terdapat hubungan negatif dengan kekuatan korelasi yang kecil baik ketika dilakukan kontrol terhadap jenis kelamin, usia, durasi penggunaan Twitter, dan jumlah tweet maupun ketika tidak dilakukan kontrol terhadap keempat variabel kontrol tersebut. Sehingga, hasil penelitian ini konsisten bahwa jika anonimitas meningkat, maka self-disclosure akan menurun.

\section{DISKUSI}

Hasil dari penelitian ini menemukan bahwa terdapat hubungan signifikan antara anonimitas dengan self-disclosure pada pengguna Twitter yang ditunjukkan dengan nilai $\mathrm{p}<0,05$. Sebelum melakukan kontrol terhadap jenis kelamin, usia, durasi penggunaan Twitter, dan jumlah tweet, ditemukan $(\mathrm{r}=0,145, \mathrm{~N}=367, \mathrm{p}=0,005)$. Kemudian, dilakukan kontrol terhadap jenis kelamin dan ditemukan $(\mathrm{r}=0,144)$. Kontrol terhadap usia menghasilkan $(\mathrm{r}=-0,190)$. Kontrol terhadap durasi menghasilkan $(\mathrm{r}=0,170)$. Kontrol terhadap jumlah tweet menghasilkan $(\mathrm{r}=-0,181)$. Dari hasil analisis terhadap keempat variabel kontrol tersebut dapat diketahui bahwa variabel-variabel tersebut memiliki pengaruh yang sangat kecil terhadap kekuatan korelasi antara anonimitas dengan self-disclosure. Maka dari itu, adanya perbedaan jenis kelamin, usia, durasi penggunaan Twitter, serta jumlah tweet hanya memberikan sedikit pengaruh terhadap hubungan antara anonimitas dan self-disclosure pada pengguna Twitter. Meskipun telah dilakukan kontrol, hubungan antara anonimitas dan self-disclosure pada pengguna Twitter tetap negatif dan memiliki kekuatan korelasi yang kecil.

Temuan pada penelitian ini berbeda dengan penelitian sebelumnya yang menemukan adanya korelasi positif antara anonimitas dengan self-disclosure dan berlawanan dengan asumsi dari online disinhibition effect, yaitu individu akan lebih mengungkapkan diri ketika dalam kondisi anonim. Korelasi negatif antar kedua variabel menunjukkan bahwa ketika anonimitas meningkat, maka self-

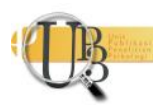


disclosure akan menurun, dan sebaliknya. Fenomena yang berbeda muncul pada penelitian ini dimana semakin tidak teridentifikasi secara visual, individu semakin kurang mengungkapkan dirinya secara mendalam. Menurut Utz dkk. (2012), terdapat faktor psikologis seperti need for popularity dan need to belong yang memengaruhi perilaku individu di media sosial seperti self-disclosure agar dapat diterima oleh orang lain, serta membangun maupun mempertahankan hubungan interpersonal. Penelitian yang dilakukan oleh Ardi \& Maison (2014) juga menemukan bahwa intimacy dari self-disclosure di Indonesia berhubungan dengan variabel-variabel psikologis seperti self-esteem, need for popularity, dan profile availability.

Penelitian yang dilakukan oleh Hollenbaugh \& Everett (2013) mendukung hasil dari penelitian ini, dimana penelitian tersebut menemukan bahwa partisipan yang lebih anonim secara visual justru kurang mengungkapkan dirinya. Selain itu, hasil penelitian serupa juga ditemukan oleh Qian \& Scott (2007). Pada penelitian tersebut, ditemukan bahwa partisipan yang lebih anonim tidak banyak mengungkapkan dirinya. Qian \& Scott (2007), hal tersebut mungkin terjadi dikarenakan individu lebih tertarik untuk diidentifikasi oleh orang lain dan mendapatkan kredit dari hal-hal yang ia bagikan kepada orang lain sehingga mereka akan mengungkapkan hal-hal yang bersifat pribadi ketika lebih teridentifikasi secara visual.

\section{SIMPULAN}

Hasil penelitian ini menemukan bahwa terdapat hubungan signifikan antara anonimitas dengan selfdisclosure pada pengguna Twitter. Korelasi antar kedua variabel memiliki kekuatan korelasi yang kecil dan terdapat korelasi negatif, yang berarti Ketika anonimitas meningkat maka self-disclosure menurun, dan sebaliknya.

\section{UCAPAN TERIMAKASIH}

Peneliti mengucapkan terima kasih kepada Allah SWT, serta keluarga dan teman-teman yang mendukung peneliti selama pengerjaan penelitian ini. Peneliti juga mengucapkan terima kasih kepada Dr. Rahkman Ardi, M.Psych. selaku dosen pembimbing yang telah banyak memberikan bimbingan dan bantuan selama pengerjaan penelitian, serta pihak-pihak lainnya yang telah membantu peneliti.

\section{DEKLARASI POTENSI TERJADINYA KONFLIK KEPENTINGAN}

Anggita Dewi Nugrahani tidak bekerja, menjadi konsultan, memiliki saham, atau menerima dana dari perusahaan atau organisasi manapun yang mungkin akan mengambil untung dari diterbitkannya naskah ini.

\section{PUSTAKA ACUAN}

Ardi, R., \& Maison, D. (2014). How do Polish and Indonesian disclose in Facebook?: Differences in online self-disclosure, need for popularity, need to belong and self-esteem. Journal of Information, Communication and Ethics in Society, 12(3), 195-218. https://doi.org/10.1108/JICES-01-20140006

Bak, J. Y., Kim, S., \& Oh, A. (2012). Self-disclosure and relationship strength in Twitter conversations. In

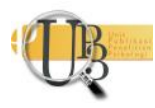


Proceedings of the Conference 50th Annual Meeting of the Association for Computational Linguistics, ACL 2012 (Volume 2:Short Papers), 60-64.

Clark-Gordon, C. V., Bowman, N. D., Goodboy, A. K., \& Wright, A. (2019). Anonymity and Online SelfDisclosure: A Meta-Analysis. Communication Reports, 32(2), 98-111. https://doi.org/10.1080/08934215.2019.1607516

Dean, B. (2021, February, 10). How Many People Use Twitter in 2021? [New Twitter Stats]. Retrieved August 28, 2021, from https://backlinko.com/Twitter-users

Deodhar, L., Divakaran, D. M., \& Gurusamy, M. (2017). Analysis of Privacy Leak on Twitter. In Proceeding of GLOBECOM 2017-2017 IEEE Global Communications Conference, 1-6. https://doi.org/10.1109/GLOCOM.2017.8254496

Dienlin, T. (2017). The psychology of privacy: Analyzing processes of media use and interpersonal communication. http://opus.uni-hohenheim.de/volltexte/2017/1315/

Gruzd, A., \& Hernández-García, Á. (2018). Privacy Concerns and Self-Disclosure in Private and Public Uses of Social Media. Cyberpsychology, Behavior, and Social Networking, 21(7), 418-428. https://doi.org/10.1089/cyber.2017.0709

Hollenbaugh, E. E., \& Everett, M. K. (2013). The effects of anonymity on self-disclosure in blogs: An application of the online disinhibition effect. Journal of Computer-Mediated Communication, 18(3), 283-302. https://doi.org/10.1111/jcc4.12008

Joinson, A. N., Houghton, D. J., Vasalou, A., \& Marder, B. L. (2011). Privacy Online. Privacy Online, 33-45. https://doi.org/10.1007/978-3-642-21521-6

Kapersky. (2021) Digital Reputation Economy Report. Retrieved August 28, 2021, from https://www.kaspersky.com/blog/digital-reputation-economy-report/

Kim, J., \& Dindia, K. (2016). Online self-disclosure : A review of research Online Self-Disclosure : A Review of Research. October, 156-180.

Komori, M., Miura, A., Matsumura, N., Hiraishi, K., \& Maeda, K. (2021). Spread of Risk Information Through Microblogs: Twitter Users with More Mutual Connections Relay News That is More Dreadful1. Japanese Psychological Research, 63(1), 1-12. https://doi.org/10.1111/jpr.12272

Krämer, N. C., \& Schäwel, J. (2020). Mastering the challenge of balancing self-disclosure and privacy in social media. Current Opinion in Psychology, 31, 67-71. https://doi.org/10.1016/j.copsyc.2019.08.003

Leung, L. (2002). Loneliness, self-disclosure, and ICQ (“I Seek You ”) use. Cyberpsychology \& Behavior, 5(3), 241-251.

Ma, X., Hancock, J., \& Naaman, M. (2016). Anonymity, intimacy and self-disclosure in social media. Proceedings of the 2016 CHI Conference on Human Factors in Computing Systems, 3857-3869. https://doi.org/10.1145/2858036.2858414

Mao, H., Shuai, X., \& Kapadia, A. (2011). Loose tweets: An analysis of privacy leaks on Twitter. Proceedings of the ACM Conference on Computer and Communications Security, 1-12. https://doi.org/10.1145/2046556.2046558 
Meeder, B., Tam, J., Kelly, P. G., \& Cranor, L. F. (2010). RT @IWantPrivacy: Widespread Violation of Privacy Settings in the Twitter Social Network. Web 2.0 Security \& Privacy, 1-12. http://w2spconf.com/2010/\%5Cnpapers3://publication/uuid/7FB63122-0D80-44FE-BE548C293088E157

Ng, T. K. (2020). Psychometric properties of the Chinese version of the Intimacy, Passion, and Commitment Scale. Current Psychology: A Journal for Diverse Perspectives on Diverse Psychological Issues, 39(1), 58-67. https://doi.org/10.1007/s12144-017-9731-4

Nguyen, M., Bin, Y. S., \& Campbell, A. (2012). Comparing online and offline self-disclosure: A systematic review. Cyberpsychology, Behavior, and Social Networking, 15(2), 103-111. https://doi.org/10.1089/cyber.2011.0277

Qian, H., \& Scott, C. R. (2007). Anonymity and self-disclosure on weblogs. Journal of Computer-Mediated Communication, 12(4), 1428-1451. https://doi.org/10.1111/j.1083-6101.2007.00380.x

Sayce, D. (2021) The Number of tweets per day in 2020. Retrieved August 28, 2021, from https://www.dsayce.com/social-media/tweets-day/

Scott, C. R., \& Rains, S. A. (2020). (Dis)connections in anonymous communication theory: exploring conceptualizations of anonymity in communication research. Annals of the International Communication Association, 44(4), 385-400. https://doi.org/10.1080/23808985.2020.1843367

Sproull, L. E. E., \& Kiesler, S. (1986). Reducing Social Context Cues: Electronic Mail in Organizational Communication. Management Science, 32(11), 1492-1512.

Suler, J. (2004). The online disinhibition effect. Cyberpsychology and Behavior, 7(3), 321-326. https://doi.org/10.1089/1094931041291295

Taddicken, M. (2014). The "Privacy Paradox" in the Social Web: The Impact of Privacy Concerns, Individual Characteristics, and the Perceived Social Relevance on Different Forms of SelfDisclosure. Journal of Computer-Mediated Communication, 19(2), 248-273. https://doi.org/10.1111/jcc4.12052

Tominaga, T., Hijikata, Y., \& Konstan, J. A. (2018). How self-disclosure in Twitter profiles relate to anonymity consciousness and usage objectives: a cross-cultural study. Journal of Computational Social Science, 1(2), 391-435. https://doi.org/10.1007/s42001-018-0023-z

Utz, S., Tanis, M., \& Vermeulen, I. (2012). It is all about being popular: The effects of need for popularity on social network site use. Cyberpsychology, Behavior, and Social Networking, 15(1), 37-42. https://doi.org/10.1089/cyber.2010.0651

Walther, J., B. (1996). Computer-Mediated Communication: Impersonal, Interpersonal and Hyperpersonal Interaction. Communication Research, 23(1), 3-43.

Wheeless, L. R., \& Grotz, J. (1976). Conceptualization and Measurement of Reported Self-Disclosure. Human Communication Research, 2(4), 338-346. https://doi.org/10.1111/j.14682958.1976.tb00494.x 